\title{
Money making technology for visually impaired people
}

\author{
A. P. Kyrychok \\ National Technical University of Ukraine "Igor Sikorsky Kyiv Polytechnic Institute", Kyiv, Ukraine \\ Corresponding author. E-mail: akyrychok@ukr.net
}

Paper received 22.12.19; Accepted for publication 30.12.19.

https://doi.org/10.31174/SEND-NT2019-215VII26-15

\begin{abstract}
This essay aims to elaborate the technology when it comes to banknote making for visually impaired members of the society. The visually impaired are divided in three subgroups: color-blind, partially sighted and blind people. Their first needs are useful denomination features rather than security features, as they help them in determining a banknote's value. This study provides a historical overview of banknote design features for the visually impaired. Furthermore, it looks into the methodology of banknote tests for the color-blind, showing images of how the color-blind experience the euro banknotes. Two features are needed for every subgroup of the visually impaired to establish the banknote's value; one is not reliable. These two features are dedicated firstly to the relevant user group, but will also be used by others, including people with normal vision.
\end{abstract}

Keywords: banknote design, visually impaired people, producing, money bill, money.

Introduction. The world has come a long way since technology was incorporated in most of the activities that human beings engage themselves. In this sense, it has played a significant role in the sector of currency production. While making different forms of currencies and banknotes it is important to consider the fact that there are people who have a visual impairment but they still need to understand the different values of banknotes that exist. So, for an individual who is visually impaired to be in a position to understand distinct values of banknotes without seeing them, then it is incumbent for the reserve banks to incorporate technology in the process of developing banknotes. It would almost appear to be impossible for a visually impaired individual to be in a position to know the value of a banknote without using their naked eyes. This discussion will be focused on exploring different types of technology deployed in making it easy for visually impaired individuals is in a position to recognize the value of different banknotes.

The necessity to design and produce banknotes that are suitable for the visually impaired comes mainly from the fact that members of this particular group make a large percentage of worldwide population; that banknotes suitable for visually impaired are suitable for all members of the society; and that this is the right thing to do and their basic human right. According to the figures managed by the World Health Organization, $5 \%$ of the world's population (253 million people) suffer from some type of visual disability, of which 36 million are totally blind, howev$\mathrm{er}$, and as a result of different inclusion initiatives implemented in most countries of the world, have adapted environments, procedures and regulations to facilitate the lives of people suffering from disabilities of some kind and the visually impaired are among the beneficiaries of these legal, infrastructure adaptations and made conformation and in progress to provide a friendlier world within its limitations and to grant them the necessary protection for their disabilities [Heij, H. de. 2009].

The people blind of birth, have a greater capacity of tactile detection than the people with normal vision or partial visual disability, according to a study of the University McMaster in Washington (the United States) published in the magazine The Journal of Neuroscience [Kyrychok, A. P. 2018a]. The brain records a vision, sound or touch in a split second, the research group, led by Daniel Goldreich, explored whether people with blind- ness would process the sense of touch more quickly. As Goldreich explains, "our findings reveal that one of the ways in which the brain adapts to the absence of vision is to accelerate the sense of touch." The ability to quickly process non-visual information probably increases the quality of life of the person. People with blindness who rely on an extraordinary degree of non-visual senses" [Wong, Gnanakumaran, \& Goldreich, 2018].

In order for the banknotes to properly serve everyone within the community, the printing process plays a significant role. Various technologies are used within different countries so as to ensure that individuals who are visually impaired also have the chance to know the value of a banknote that they are using [Springer et al, 2015]. Through technology, reserved banks have over the years continued to improve on the appearance and security of these banknotes. There are security features that can be reorganized by an individual even without having a clear look on the note. The size and the texture of banknotes have continued to improve as new technology continues to be incorporated in the production process.

Main text of the article. Depending on the levels of consultation from each country they influence the type of technology that will be deployed in manufacturing banknotes that have features that are of assistance to individuals with visual impairment. The fact that there are countries that have banknotes with similar size then a different type of technology has to be devised to address the problem [Kyrychok, A. P. 2018b]. This is a problem especially with the United States which has all its dollars bills in the same size. In such a scenario, then it becomes incumbent for another type of technology that is more advanced to be deployed in place. Thus, the country is usually more interested in making devices that will make the process of denominating banknotes easier for individuals with visual impairment [Laming, D. R. J. 1986].

Different countries have come up with different forms of technology which they use to help visually impaired individuals to identify banknotes. According to the form of technology available in a certain country, they are the ones that determine the overall appearance of a banknote to serve both the visually impaired and the normal individuals using these banknotes. The United States remains to the only country in the world that prints all her banknotes with the same size. On the color issue, the only two countries in the world that use different bills with the 
same color in the world are Switzerland and the United States. This similarity in color and size makes it difficult for visually impaired individuals to differentiate different bills used in the country. It is in public domain that even people with partial visual challenges find it difficult to distinguish between $\$ 1$ from a $\$ 10$ bill especially those that have to circulate for long. Such challenges have called in for the need to have various technology invented for the purposes of ensuring that these bills are easily recognized by visually impaired individuals.

One of the technology solutions that have come in place is the iBill talking banknote identifier. This is a form of technology that is deployed through a simple gadget that has the ability to read the value of different bills. These gadgets were commonly used by private companies that had high technology of identifying bills that came through their organization until currently, they started producing these currency identifiers for public use. It is a small gadget with a sensor that has the ability to read, identify and announce the denomination of a bill when inserted on the in it. To handle all these visually impaired individual cases related to identifying various bills, now the iBill Talking Banknote Identifiers are available for free in America only for American citizens who can access them from the Treasury Department. This is quite a good move by the American government in addressing the issue. The gadget is very comfortable to use as it is small enough to fit in the pocket of an individual using it. Provided the bill is not damaged or crumpled then the bill has the ability to identify all types of bill circulating within the U.S economy.

Apart from the iBill solution provided by the Treasury Department, there are also some mobile phone applications that can be utilized by a visually impaired individual to identify a bill. The mobile phone applications are not many but the few available operate on both Android and iOS platforms which rely on the phones' cameras to read the value of a bill. This technology makes it easy for every individual with visual impairment to exploit his/her phone to detect the value of a bill. With just pointing the face of the bill whether rear or front side on the camera of a phone then within a few seconds it will be identified and then read to the individual. The reason behind these banknotes being recognized is that they have various authorized security features which are sensed when putting under the gadget. The best thing with the device is that when an individual who is visually impaired is given a banknote that is not legit, it will not be recognized. Thus, from this point, we can see that there are two types of advantages that we get from working with the device.

Different countries have utilized technology through tactile features being applied on the banknotes to help blind individuals to functionally be able to denominate banknotes. This technology began in Canada where it was thought that through using the sense of touch it would be easy to understand the type of note that an individual is having [Samuel, 2010]. Through a series of texture feature design denomination on different bills, it has become easy for visually impaired individuals to denominate various banknotes. The bills that are being used in Canada are designed in a way that they have a tactile code which has texture difference from one bill to another [Samuel, 2010]. This is an implication that when an individual with different bills he/she can distinguish them by feeling the texture on them. The technology that was used in developing these bills ensured that the type of material used was in a position to accommodate different patterns on it [Samuel, 2010]. In Zambia, there is a different type of technology that is utilized for making it easy for different visually impaired individuals to identify banknotes. Even though the technology used here cannot be credited as being sophisticated, it still serves well for the visually impaired people of Zambia [Lederman \& Hamilto, 2002]. As one of Zambia's most important role is to ensure that the notes produced are able to serve across every highly valued individual with vision impairment.

The Bank of Zambia has since then taken the chance to utilize technology in incorporating special marks on various bills. These special marks are usually in the form of slanting lines which are printed in raised ink. For every denomination, there are a certain number of the special lines which range from 2 lines in a K2 bill, 3 lines for a k5 banknote, 4 lines for a k10 note, 5 lines for a k20 note and lines for k1000 banknotes [Lederman \& Hamilto, 2002]. These notes were released into circulation in the year 2015 and they have proved to be of significance to the population. The Bank of Zambia has continued to work in collaboration with the Zambia National Federation of the Blind [ZANFOB] to devising new technology that should be incorporated in reprinting banknotes [Lederman \& Hamilto, 2002]. The technology being used in Zambia is more concerned with improving the textual features of all bills for the visually impaired. Since 2015 to 2017 the banknotes that were produced by the Zambian Bank have a much-intensified intaglio which has made their textures to vary.

In Australia, a different form of technology is in progress which is deploying improvements on the entire structure of the banknotes. As it is with other Reserve Banks, the role of Australian Reserve Bank is to ensure that all banknotes are designed and produced in a manner that meets all the requirements that will allow servicing all areas of the community [RBA, 2012]. Since 1960, Australia devised the paper decimal banknote series. This technology ensured that all the banknotes produced were in different sizes which increased in size chronologically in relation to the value of the banknote. The banknotes here have different lengths with large numerical figures which make them easy to be identified. The current banknotes of $\$ 50$ and $\$ 100$ that is in use in Australia have a length difference of $7 \mathrm{~mm}$ between each [RBA, 2012]. The color distinction is also another technology deployed in this country to ensure that visually impaired persons are able to differentiate different banknotes [RBA, 2012]. The length difference is something that can be easily distinguished by a visually impaired individual in that the banknote with the smallest length denominates a smaller value while the one with the longest length stands for a bigger value of a banknote.

Through technology, there are various differential features that range from color, length, and size that makes it easy for people with visual impairments to identify the banknotes. The $\$ 5$ banknote has lines running horizontally across the note which appear to be parallel [Currency Features for Visually Impaired People 1995]. The numerical figure representing the value of the banknote is also 
large such that it can be noticed with just a slight look on the note. The $\$ 10$ banknote has lines crossing each other forming a pattern that seems like a mesh which is different from that of the $\$ 5$ banknote [Butterly, A. 2016]. The \$20 banknote has lines running vertically along with the banknote's height which makes the pattern different from the rest of the banknotes. In this case, the texture is the technology exploited although this is not all as there is still more project that has come up since then [BBC Newsbeat]. It has also prevented counterfeiters from changing the value of the banknotes as it is difficult for them to have all these patterns fit on the banknotes that they have developed [Киричок, А. П., Мельниченко, А. A. 2013]. The technology used here is very sensitive and secretive in that counterfeiters cannot be able to copy and destroy what is meant to help people with visual impairment.

A banknote-measuring device is a gadget that was specifically developed to help in reading various banknotes. Through technology, it offers aid to partially and fully visually impaired individuals to identify banknotes. It is a plastic device that is easy to operate and carry as it has a standard size that can enable it to fit in a wallet. The device is operated through inserting a banknote into it and folds it then touch on the brail which gives the actual amount to the individual [Kyrychok, A. P. 2018a]. It has braille on one side that helps those who are fully impaired visually to have an exact deduction on what the value of the banknote. It has played a significant role in visually impaired persons as it is now easy to do shopping and trade with different individuals (RBA, 2012). The challenge with these devices is that they are not readily available to all individuals considered as being visually impaired [Springer et al, 2015]. As much as technology is being made to help out in the situation, it should also be made available to all individuals within different countries under the same proportions. The technology seems to be only available to those that have high visions within different countries.

The New Zealand Bank is another reserve bank that has decided to take upon improving the security and resemblance of their banknotes. For the development of banknotes that are in the next series of technology is incorporated so as to ensure that they meet the required standards functional requirements and aesthetic culture [Kyrychok, A. P. 2018a]. The designs on these banknotes have had several challenges since the increase in counterfeit cases in the country. They have devised varied tactical means that through touching the banknote visually impaired individuals to identify various bills. In this case, counterfeit banknotes do not have a rough texture as it is with an original one which gives the difference between the two [Kyrychok, A. P. 2018a]. The material also used to make counterfeit banknotes are from paper which is not as durable as the cotton and polymer materials used to make the original ones. There are also some other security features in the fake bank materials that do not appear within the banknotes.

There are different color schemes that are currently in use to differentiate various banknotes. The color schemes are made in a brighter manner that makes them easily analyzed. The colors in the banknotes are developed under a technology that makes them be in a position not to make it difficult for partially impaired individuals recognize them [Matua, 2014]. The different colors are logically interchanged in a manner that each color shifts to the next in a way that the difference between each banknote can be in a sequential manner [Kyrychok, A. P. 2018b]. Green appears to be the secondary color for the largest banknote which makes it easy to be recognized [Springer et al, 2015]. In order to cater to the visually impaired individuals, it is important for the developers of these banknotes to be aware of all the challenges.

Color serves a significant role in denominating different banknotes, for this reason, each banknote needs to be provided with a specific predominant color. For instance, the $\$ 100$ could be assigned a blue color constantly each time when produced. An individual with low vision can utilize the color of a note bank rather than when there is large numeric on the note. Technology has then developed specific colors which are usually associated with specific banknotes [Lederman \& Hamilto, 2002]. It has led to different colors to represent a certain value this will means that even without having a closer look at the banknote it will be easy to identify it.

There are two distinct common printing technologies that are used to produce banknotes which are of significance to the visually impaired individuals. Through intaglio printing and letterpress, it is easy for an individual to just touch the banknote and read it in his/her mind even without having a look [Lederman \& Hamilto, 2002]. Different countries use varied colors while utilizing the lithographic printing technology although green color appears to one of the most common colors being utilized [Springer et al, 2015]. It is advisable that for the visually impaired individuals to be served with banknotes which have a monochrome color this is because the color may be easy to identify.

The current banknote printing process incorporates the use of two important techniques that ensures all the community members regardless of their disabilities they are able to use the money easily. There is the engraving using a cutting tool that removes some part of the banknote hence making a rough surface etching is also another method whereby a chemical substance is used to remove some part of a metal plate that is in turn used to make banknotes through the compression process [Kyrychok, A. P. 2018b]. A lot of pressure is exerted on a metal plate that has all the features required to be on a banknote [Kyrychok, A. P. 2018b]. Ink is then applied on the surface of the metal plate then transferred on the required piece of paper that is supposed to be used as a banknote. The color of the ink is left on the paper with high relief which makes them highly reflective.

The material that is used to make these banknotes is also a very significant part of the technology used to aid visually impaired individuals in the denomination process. The two major materials that are used to produce most of the banknotes include polymer and cotton fiber. These are then printed through offset, intaglio printing and screen-printing [RBA, 2012]. Banknotes that are made from polymer include a first step which involves preparation of a substance base substrate of polymer which tends to become opaque during the process of sheet preparation [RBA, 2012]. The technology used in the production makes the banknotes made of polymer become 
resistant to different forms of damages and worn out. It is clear that when the banknotes become weary, they are difficult to identify as they tend to lose some features which are important in their identification process.

Despite technology being used in the process of developing more improvised banknotes, there are a number of challenges that are encountered in the process which makes the entire banknote production process under threat. The first challenge that is being faced across all countries in the process of producing new banknotes is counterfeiting [Kyrychok, A. P. 2018b]. Over the past few years, the rate at which counterfeit banknotes are being produced has increased which has made it difficult for reserved banks to constantly produce banknotes in bulk [Lederman \& Hamilto, 2002]. Instead, it has made reserved banks and other shareholders involved in the production of money to focus a lot on improving the security features of these banknotes rather than incorporating features that would aid visually impaired individuals [Springer et al, 2015]. It would be useless to increase on the number of banknotes while they are being counterfeited which calls in the need to incorporate technology in not only catering for the visually impaired individuals but also security features need to be improved.

Another issue is ensuring that the money produced does not affect the currency value of the country. This comes as a result of money being overproduced in a country until they lose their values. Despite the fact that countries may be interested in making more money that are of assistance to the visually impaired community they should also be controlling the flow of funds which is a problem that may lead to a financial crisis within the country (Samuel, 2010). For various reasons that are seeming to be a threat to the banknote production process technology should be much concentrated on creating devices that detect the value of money rather than reproducing the current exiting currencies.

Conclusion. Conclusively, technology has played a significant role in aiding visually impaired individuals to operate swiftly with banknotes. Were it not for technology, people with full visual impairment would be having a difficult time in determining the value of a banknote while conducting their financial endeavors. Through technology, it has become easy for visually impaired individuals in different countries to exploit their tactile abilities to detect the value of a banknote. It would also be important for countries to be doing deep research and consultation so as to decide which technology would be best applied to helping visually impaired individuals comprehend different banknote denominations. Human beings should always be ready to help each other in situations such as the ones that fully blind and partially visually impaired individuals are undergoing while engaging in financial related issues. Despite technology trying to help out visually impaired individuals in handling banknotes, reserved banks should not forget that there are always challenges trying to counter their work which requires them to be always prepared.
1. BBC Newsbeat. Available at: http://www.bbc.co.uk/newsbeat/article/37231241/how-newbank-notes-willhelp-the-visually-impaired-community Last accessed: 12.03 .2018

2. Butterly, A. (2016, August 31). How new banknotes will help the visually-impaired community.

3. Currency Features for Visually Impaired People (1995). doi: $10.17226 / 4828$

4. Grijalva, F., Rodriguez, J. C., Larco, J., \& Orozco, L. (2010). Smartphone recognition of the U.S. banknotes' denomination, for visually impaired people. 2010 IEEE ANDESCON. doi:10.1109/andescon.2010.5631773

5. Heij, H. de. (2009). Banknote design for the visually impaired Vol. 7. Occasional Studies, 168.

6. Kyrychok, A. P. (2018a). The overview of investigation in the field of banknote design for visually impaired people. Eureka: physics and engineering, 3, 33-41.

7. Laming, D. R. J. (1986). Sensory Analysis. San Diego: Academic Press.

8. Lederman SJ and C Hamilton (2002), 'Using Tactile Features

\section{FERENCES}

to Help Functionally Blind Individuals Denominate Banknotes', Human Factors, 44(3), pp 413-428.

9. Matua, T. P. (2014). Bulletin. Reserve Bank of New Zealand, 77(7).

10. RBA (Reserve Bank of Australia) (2012), 'Upgrading Australia's Banknotes', Media Release No 2012-27, 27September.

11. Samuel C (2010), 'Making Banknotes Accessible for Canadians Living with Blindness or Low Vision,' Bank of Canada Review, Winter 2009-2010, pp 29-36.

12. Springer, K., Subramanian, P., \& Turton, T. (2015). Assisting People with Vision Impairment. Australian Banknotes.

13. Киричок, А. П., Мельниченко, А. А. (2013). Грошова культура населення в контексті дослідження соціальних комунікацій. Вісник Книжкової палати, 12, 42-43.

14. Kyrychok, A. P. (2018b). Money bill technology of tactile recognition engrav-ings for visually impaired. Science and education a new dimention, 6, 33-36. 